\title{
Ecological niche of weeds in spring cereals cultivars grown after winter oilseed rape
}

\author{
Nisza ekologiczna chwastów w odmianach zbóż jarych \\ uprawianych po rzepaku ozimym
}

\author{
Marek Urban ${ }^{1}$, Kazimierz Adamczewski ${ }^{2}$, Adam Dobrzański ${ }^{3}$
}

\section{Summary}

The environmental conditions and ecological niches for weed survival and development in cereals crops are diversified. They are conditioned by biotic and abiotic factors of the environment and natural factors including quantitative rations between species of agrophytocenosis.

The object of the studies carried out in 2009-2012 was to determine the weed species composition and infestation in crops of spring cereal species. Two cultivars were taken into consideration for each cereal species. The observations were done on the control (untreated) plots of a field experiment on evaluation of herbicide biological efficacy. The obtained results revealed that regardless of cereal species and cultivar, the weed species composition was similar, however the number of weeds and their biomass were different. The smaller weed biomass and their number were correlated with a higher competitiveness of cultivated cereal plants in relation to weeds. The rye cultivar Bojko showed the highest competitivenes, while the wheat cultivar Tybalt was the least competitive. The highest weed infestation was recorder for wheat in contrast to the lowest one in barley and rye crops. A proper selection of cereal species and cultivars with high competitive abilities should be taken into consideration by organic farms.

Key words: weeds, spring cereals cultivars, ecological niche, biocenotic index

\section{Streszczenie}

Warunki życia chwastów i nisze ekologiczne w zasiewach rożnych gatunków zbóż nie są jednakowe. Zależą one od zespołu biotycznych i abiotycznych czynników środowiska i całokształtu czynników przyrodniczych, w tym od stosunków ilościowych pomiędzy różnymi gatunkami tworzącymi agrofitocenozę. W badaniach wykonanych w latach 2009-2012 określono skład florystyczny i stopień zachwaszczenia w 5 gatunkach zbóż jarych, przy czym w każdym gatunku uwzględniono 2 odmiany. Obserwacje przeprowadzono w obiektach kontrolnych doświadczeń z oceną skuteczności biologicznej herbicydów. Uzyskane wyniki wskazują, że niezależnie od gatunku i odmiany liczba występujących taksonów kształtowała się podobnie, natomiast ich liczebność i biomasa ulegała dużemu zróżnicowaniu w zależności od uprawianych gatunków i odmian zbóż jarych. Im mniejsza była liczba i biomasa chwastów, tym większa była konkurencyjność uprawianych roślin w stosunku do chwastów. Największą konkurencyjnością charakteryzowało się żyto odmiany Bojko, a najmniejszą pszenica odmiany Tybalt. Największe zachwaszczenie wyrażone zarówno ogólną liczbą chwastów i biomasą odnotowano w pszenicy a najmniejsze w jęczmieniu i w życie. Wybór do uprawy gatunków i odmian zbóż jarych o większej zdolności konkurencyjnej powinien być uwzględniany w gospodarstwach ekologicznych.

Słowa kluczowe: chwasty, odmiany zbóż jarych, nisza ekologiczna, wskaźnik biocenotyczny

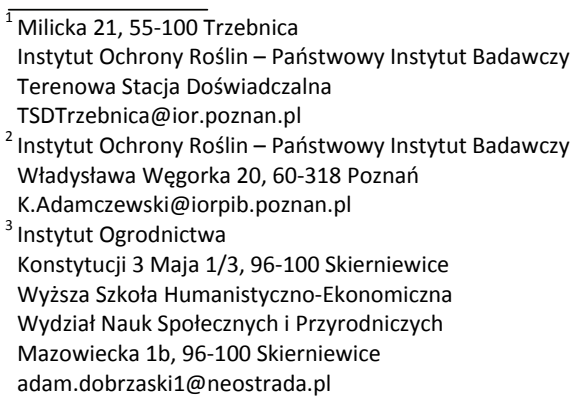




\section{Wstęp / Introduction}

Nisze ekologiczne w obrębie biotopu agrofitocenozy różnią się pomiędzy sobą oświetleniem powierzchni gleby (Markow 1978), co może być uzależnione od cech morfologicznych roślin uprawnych i chwastów oraz zdolności do zakrywania powierzchni przez różne gatunki a nawet odmiany (Smith 1974; Sweet 1976; Hucl 1998; Jędruszczak i wsp. 2004; Parylak i wsp. 2006; Abouziena i wsp. 2008). Między innymi, dlatego mogą się one różnić pomiędzy sobą zdolnością konkurencyjną w stosunku do chwastów. Wynikiem tego mogą być różnice w składzie gatunkowym chwastów i w zależnościach pomiędzy rośliną uprawną a chwastami, wynikające z konkurencji międzygatunkowej o miejsce w niszy ekologicznej. Wybór do uprawy gatunków i odmian o dużych właściwościach konkurencyjnych w stosunku do chwastów może być uzupełnieniem innych metod regulacji zachwaszczenia (Christensen 1994, 1995; Lemerle i wsp. 1996; Seavers i Wright 1999; Wicks i wsp. 2004; Mennan i Zandstra 2005; Parylak i wsp. 2006). Informacje, jak kształtuje się układ stosunków biocenotycznych w zależności od uprawianych gatunków i odmian zbóż jarych, przejawiające się zróżnicowaniem stanu i stopnia zachwaszczenia, mogą być pomocne do opracowywania systemów wspomagania decyzji o konieczności zwalczania chwastów i wyborze gatunków i odmian w integrowanej i ekologicznej ochronie przed chwastami.

Celem badań było określenie składu florystycznego i stopnia zachwaszczenia w 5 gatunkach zbóż jarych: pszenicy (odmiany: Tybalt i Parabola), jęczmieniu (odmiany: Mauritia i Stratus), owsie (odmiany: Arden i Haker), pszenżycie (odmiany: Nagano i Andrus), życie (odmiany: Bojko i Arantes).

\section{Materiały i metody / Materials and methods}

Badania polowe przeprowadzono w latach 2009-2012 w Stacji Doświadczalnej Oceny Odmian Krościna Mała (województwo dolnośląskie). W pszenicy i jęczmieniu badania prowadzono 3 lata; a owsie, pszenżycie i życie -
2 lata. Obserwacje zachwaszczenia przeprowadzono w obiektach kontrolnych doświadczeń, w których oceniano skuteczność biologiczną herbicydów założonych w 4 powtórzeniach, na poletkach o powierzchni $16,5 \mathrm{~m}^{2}$ zlokalizowanych na glebie płowej klasy IVa. Przedplonem we wszystkich sezonach wegetacyjnych był rzepak ozimy. Norma wysiewu i inne zabiegi były zgodne z zaleceniami agrotechnicznymi. Zbiorowiska chwastów scharakteryzowano na podstawie liczebności taksonów i świeżej biomasy chwastów na $1 \mathrm{~m}^{2}$ (metoda ramkowa i wagowa) określonej w fazie strzelania w źdźbło oraz wskaźników biocenotycznych, takich jak: bioróżnorodność gatunkowa $\left(H^{\prime}\right)$, dominacja (C), równomierność rozmieszczenia gatunków (J) dla wskaźnika Shannona (Shannon i Weaver 1963; Falińska 2004). Wysokość zbóż oraz obsadę źdźbeł kłosonośnych na $1 \mathrm{~m}^{2}$ określono bezpośrednio przed zbiorem.

\section{Wyniki i dyskusja / Results and discussion}

Gatunki i odmiany zbóż jarych, w uprawie których prowadzono obserwacje zachwaszczenia różniły się wysokością i obsadą kłosów w czasie zbioru (tab. 1). Cechy te zależą w dużym stopniu od zagęszczenia roślin w łanie oraz stopnia rozkrzewienia, co jest uwarunkowane odmianami w obrębie poszczególnych gatunków zbóż. Miało to wpływ na ogólną liczbę chwastów i ich biomasę. Uzyskane wyniki wskazują, że niezależnie od gatunku i odmiany liczba występujących taksonów w latach była różna, ale średnio dla lat kształtowała się podobnie, natomiast ich liczebność i biomasa ulegała pewnemu zróżnicowaniu w zależności od uprawianych gatunków i odmian zbóż jarych. Najmniej korzystne dla chwastów były nisze ekologiczne w uprawie żyta i jęczmienia, a więc gatunków zazwyczaj silniej się krzewiących w porównaniu $\mathrm{Z}$ innymi zbożami. W gatunkach tych odnotowano najmniejszą ogólną liczbę i biomasę chwastów. Natomiast w badaniach Rudnickiego (1994) zaobserwowano, że u trzech gatunków zbóż jarych (jęczmień, pszenica, owies) liczba występujących chwastów kształtowała się podobnie, ale stwierdzono różnice $w$ ich masie, przy czym najmniejszą

Tabela 1. Liczba kłosów i wysokość roślin oraz liczebność i biomasa chwastów w 2 odmianach 5 gatunków zbóż jarych Table 1. Ears number and plants height as well as weed number and biomass in 2 cultivars of 5 spring cereals species

\begin{tabular}{|c|c|c|c|c|c|c|c|c|c|}
\hline \multirow{2}{*}{$\begin{array}{l}\text { Gatunek } \\
\text { Species }\end{array}$} & \multirow{2}{*}{$\begin{array}{l}\text { Odmiany } \\
\text { Cultivars }\end{array}$} & \multicolumn{2}{|c|}{$\begin{array}{l}\text { Liczba kłosów } \\
\text { Ears number }\end{array}$} & \multicolumn{2}{|c|}{$\begin{array}{l}\text { Wysokość roślin } \\
\text { Plants height }\end{array}$} & \multicolumn{2}{|c|}{$\begin{array}{l}\text { Liczba chwastów } \\
\text { Weed number }\end{array}$} & \multicolumn{2}{|c|}{$\begin{array}{l}\text { Biomasa chwastów } \\
\text { Weed biomass }\end{array}$} \\
\hline & & $\begin{array}{l}{\left[\mathrm{szt} . / \mathrm{m}^{2}\right]} \\
{\left[\mathrm{pcs} / \mathrm{m}^{2}\right]}\end{array}$ & $\begin{array}{c}\text { średnie } \\
\text { mean }\end{array}$ & {$[\mathrm{cm}]$} & $\begin{array}{c}\text { średnie } \\
\text { mean }\end{array}$ & $\begin{array}{l}{\left[\mathrm{szt} . / \mathrm{m}^{2}\right]} \\
{\left[\mathrm{pcs} / \mathrm{m}^{2}\right]}\end{array}$ & $\begin{array}{c}\text { średnie } \\
\text { mean }\end{array}$ & {$\left[\mathrm{g} / \mathrm{m}^{2}\right]$} & $\begin{array}{c}\text { średnie } \\
\text { mean }\end{array}$ \\
\hline $\begin{array}{l}\text { Pszenica } \\
\text { Wheat }\end{array}$ & $\begin{array}{c}\text { Tybalt } \\
\text { Parabola }\end{array}$ & $\begin{array}{l}544 \\
495\end{array}$ & 519 & $\begin{array}{l}79 \\
89\end{array}$ & 84 & $\begin{array}{l}73 \\
69\end{array}$ & 71 & $\begin{array}{l}338 \\
304\end{array}$ & 321 \\
\hline $\begin{array}{l}\text { Jęczmień } \\
\text { Barley }\end{array}$ & $\begin{array}{l}\text { Stratus } \\
\text { Mauritus }\end{array}$ & $\begin{array}{l}722 \\
711 \\
\end{array}$ & 717 & $\begin{array}{l}78 \\
75\end{array}$ & 76 & $\begin{array}{l}62 \\
47\end{array}$ & 54 & $\begin{array}{l}267 \\
202\end{array}$ & 234 \\
\hline $\begin{array}{l}\text { Owies } \\
\text { Oats }\end{array}$ & $\begin{array}{l}\text { Arden } \\
\text { Haker }\end{array}$ & $\begin{array}{l}417 \\
428\end{array}$ & 422 & $\begin{array}{l}88 \\
89\end{array}$ & 88 & $\begin{array}{l}66 \\
55\end{array}$ & 60 & $\begin{array}{l}298 \\
237\end{array}$ & 268 \\
\hline $\begin{array}{l}\text { Pszenżyto } \\
\text { Triticale }\end{array}$ & $\begin{array}{l}\text { Nagano } \\
\text { Andrus }\end{array}$ & $\begin{array}{l}404 \\
450\end{array}$ & 427 & $\begin{array}{c}95 \\
105\end{array}$ & 100 & $\begin{array}{l}63 \\
63\end{array}$ & 63 & $\begin{array}{l}291 \\
271\end{array}$ & 281 \\
\hline $\begin{array}{l}\text { Żyto } \\
\text { Rye }\end{array}$ & $\begin{array}{l}\text { Arantes } \\
\text { Bojko }\end{array}$ & $\begin{array}{l}452 \\
455 \\
\end{array}$ & 453 & $\begin{array}{l}132 \\
127 \\
\end{array}$ & 129 & $\begin{array}{l}56 \\
48 \\
\end{array}$ & 52 & $\begin{array}{l}224 \\
247 \\
\end{array}$ & 236 \\
\hline
\end{tabular}


masę wytworzyły chwasty w jęczmieniu. Także Kapeluszny (1994) podaje, że przyrost biomasy chwastów w łanie pszenicy jarej był dwu-, trzykrotnie wyższy niż w jęczmieniu jarym. Największe zachwaszczenie, niezależnie od odmiany stwierdzono w pszenicy, przy czym różnice w ogólnej liczebności chwastów pomiędzy odmianami były stosunkowo niewielkie. Największe różnice odmianowe w ogólnej liczebności chwastów wystapiły w jęczmieniu, owsie i życie (tab. 1). W porównywanych zbożach zaznaczyły się różnice pomiędzy odmianami w biomasie chwastów, mianowicie: w pszenicy biomasa chwastów była większa w odmianie Tybalt niż w odmianie Parabola, w jęczmieniu w odmianie Stratus niż Mauritia, w owsie w odmianie Arden niż Haker. Biomasa chwastów wytworzona w odmianie pszenżyta Andrus była mniejsza niż w odmianie Nagano. Żyto odmiany Bojko było bardziej zachwaszczone niż Arantes (tab. 1). Analiza składu florystycznego wykonana na podstawie średniej $\mathrm{z}$ lat wykazała, że w zbożach jarych niezależnie od gatunku i odmiany był on zbliżony, aczkolwiek stwierdzono pewne różnice w liczebności taksonów. W pszenicy, najbardziej ulegającej zachwaszczeniu, zaobserwowano 14 gatunków, w jęczmieniu 13, w owsie i pszenżycie 10. W najmniej zachwaszczonym życie występowało 9 gatunków. We wszystkich zbożach chwastem dominującym były samosiewy rzepaku (Brassica napus var. oleifera). Liczebność tych samosiewów była niemal w każdym roku badań wyższa $\mathrm{w}$ porównaniu $\mathrm{z}$ innymi częściej notowanymi taksonami. W pszenicy udział samosiewów rzepaku ozimego w zbiorowisku chwastów, w zależności od odmiany wynosił od 31,8 (odmiana Parabola) do 34,6\% (odmiana Tybalt), a w życie od 28,4 (odmiana Bojko) do 33,9\% (odmiana Arantes) (tab. 2). Różnice te zostały także potwierdzone wskaźnikiem dominacji C, który dla rzepaku we wszystkich zbożach niezależnie od odmiany był najwyższy i np. w pszenicy oraz życie wynosił 0,06-0,07 (tab. 3). Wynikało to stąd, że zboża uprawiane były w stanowiskach po rzepaku ozimym. Masowe pojawianie się wkrótce po wschodach szybko rosnących roślin rzepaku, konkurujących o miejsce w niszy ekologicznej nie tylko ze zbożami, ale też $\mathrm{z}$ chwastami właściwymi ograniczało liczebność tych ostatnich. $\mathrm{Na}$ drugim miejscu pod względem liczebności była komosa biała (Chenopodium album). Liczebność tego chwastu zależała wyraźnie od rodzaju uprawianych zbóż. Najwięcej roślin komosy białej stwierdzono w pszenicy. W obydwu odmianach jej liczebność była niemal jednakowa (około 19 szt. $/ \mathrm{m}^{2}$ ), co odpowiadało udziałowi w zbiorowisku wynoszącym 25,9-27,3\% i wskaźnikowi C $(0,04-0,05)$. Podobnie kształtowało się zachwaszczenie tym gatunkiem w innych zbożach, aczkolwiek zaznaczyły się tu różnice pomiędzy odmianami, z wyjątkiem owsa i żyta. W jęczmieniu liczba roślin Ch. album wynosiła 7,1 (odmiana Mauritia) i $13,2 \mathrm{szt} . / \mathrm{m}^{2}$ (odmiana Stratus), to jest odpowiednio 15,1 i $21,4 \%$. W pszenżycie, w odmiane Nagano stwierdzono obecność komosy białej w liczbie $10,5 \mathrm{szt} . / \mathrm{m}^{2}(17,3 \%)$, a w odmianie Andrus - 18,5 szt./m² $(29,6 \%)$. Wskaźnik C

Tabela 2. Udział gatunków chwastów w procentach, w zbiorowisku, w 2 odmianach 5 rodzajów zbóż jarych

Table 2. Share of species in weed community at percent, in 2 cultivars of 5 spring cereals species

\begin{tabular}{|c|c|c|c|c|c|c|c|c|c|c|}
\hline \multirow{2}{*}{$\begin{array}{l}\text { Gatunki } \\
\text { Species }\end{array}$} & \multicolumn{2}{|c|}{$\begin{array}{l}\text { Pszenica } \\
\text { Wheat }\end{array}$} & \multicolumn{2}{|c|}{$\begin{array}{l}\text { Jęczmień } \\
\text { Barley }\end{array}$} & \multicolumn{2}{|c|}{$\begin{array}{c}\text { Owies } \\
\text { Oats }\end{array}$} & \multicolumn{2}{|c|}{$\begin{array}{l}\text { Pszenżyto } \\
\text { Triticale }\end{array}$} & \multicolumn{2}{|c|}{$\begin{array}{l}\text { Żyto } \\
\text { Rye }\end{array}$} \\
\hline & Tybalt & $\begin{array}{c}\text { Para- } \\
\text { bola }\end{array}$ & Stratus & $\begin{array}{l}\text { Mauri- } \\
\text { tius }\end{array}$ & Arden & Haker & Nagano & Andrus & Arantes & Bojko \\
\hline Brassica napus & 34,6 & 31,8 & 27,3 & 21,4 & 33,9 & 26,6 & 23,6 & 30,6 & 33,9 & 28,4 \\
\hline Chenopodium album & 25,9 & 27,3 & 21,4 & 15,1 & 18,7 & 20,1 & 17,3 & 29,6 & 21,5 & 21,4 \\
\hline Galium aparine & 8,8 & 8,3 & 9,5 & 13,0 & 12,2 & 10,3 & 12,0 & 10,0 & 13,6 & 16,6 \\
\hline Stellaria media & 2,7 & 2,8 & 7,3 & 8,0 & 6,0 & 5,9 & 2,6 & 0 & 14,0 & 5,8 \\
\hline Geranium pusillum & 5,2 & 8,2 & 6,1 & 7,0 & 0 & 0 & 8,7 & 4,7 & 5,9 & 4,8 \\
\hline Viola arvensis & 3,1 & 3,2 & 7,1 & 8,5 & 5,1 & 5,3 & 5,5 & 4,2 & 11,6 & 13,1 \\
\hline Lamium purpureum & 4,1 & 4,2 & 6,3 & 7,9 & 9,3 & 9,9 & 7,2 & 8,3 & 0 & 0 \\
\hline L. amplexicaule & 2,2 & 1,5 & 2,9 & 4,0 & 6,3 & 7,1 & 8,4 & 6,1 & 7,9 & 3,7 \\
\hline Fallopia convolvulus & 1,4 & 0,3 & 1,0 & 0,9 & 6,8 & 5,7 & 9,2 & 5,2 & 2,4 & 0 \\
\hline Veronica persicaria & 0,1 & 0,3 & 2,6 & 3,2 & 1,1 & 0,8 & 0 & 0 & 0 & 4,6 \\
\hline Thlaspi arvense & 6,2 & 6,4 & 2,9 & 3,2 & 0 & 0 & 0 & 0 & 0 & 0 \\
\hline $\begin{array}{l}\text { Matricaria maritima } \\
\text { sp. inodora }\end{array}$ & 2,5 & 2,8 & 0 & 0 & 0 & 0 & 0 & 0 & 2,8 & 1,6 \\
\hline Cirsium arvense & 0,4 & 0,3 & 0,3 & 0,4 & 0,6 & 8,3 & 5,5 & 0,6 & 0 & 0 \\
\hline Convolvulus arvense & 2,8 & 2,8 & 5,3 & 7,4 & 0 & 0 & 0 & 0 & 0 & 0 \\
\hline $\begin{array}{l}\text { Liczba gaunków } \\
\text { Species number }\end{array}$ & 14 & 14 & 13 & 13 & 10 & 10 & 10 & 10 & 9 & 9 \\
\hline $\begin{array}{l}\text { Ogółem }\left[\mathrm{szt} . / \mathrm{m}^{2}\right] \\
\text { Total }\left[\mathrm{pcs} / \mathrm{m}^{2}\right]\end{array}$ & 73,1 & 68,6 & 61,8 & 47,0 & 60,9 & 49,3 & 60,7 & 62,3 & 49,3 & 34,5 \\
\hline
\end{tabular}


Tabela 3. Wartość wskaźnika dominacji (C) gatunków chwastów w 2 odmianach 5 gatunków zbóż jarych

Table 3. Value of dominance coefficients (C) of species at weed community in 2 cultivars of 5 spring cereals species

\begin{tabular}{|c|c|c|c|c|c|c|c|c|c|c|}
\hline \multirow{2}{*}{$\begin{array}{l}\text { Gatunki } \\
\text { Species }\end{array}$} & \multicolumn{2}{|c|}{$\begin{array}{l}\text { Pszenica } \\
\text { Wheat }\end{array}$} & \multicolumn{2}{|c|}{$\begin{array}{c}\text { Jęczmień } \\
\text { Barley }\end{array}$} & \multicolumn{2}{|c|}{$\begin{array}{l}\text { Owies } \\
\text { Oats }\end{array}$} & \multicolumn{2}{|c|}{$\begin{array}{l}\text { Pszenżyto } \\
\text { Triticale }\end{array}$} & \multicolumn{2}{|c|}{$\begin{array}{l}\text { Żyto } \\
\text { Rye }\end{array}$} \\
\hline & Tybalt & $\begin{array}{l}\text { Para- } \\
\text { bola }\end{array}$ & Stratus & Mauritius & Arden & Haker & Nagano & Andrus & Arantas & Bojko \\
\hline Brassica napus & 0,07 & 0,06 & 0,04 & 0,02 & 0,08 & 0,04 & 0,04 & 0,08 & 0,07 & 0,06 \\
\hline Chenopodium album & 0,04 & 0,05 & 0,03 & 0,01 & 0,02 & 0,02 & 0,02 & 0,08 & 0,03 & 0,03 \\
\hline Galium aparine & + & + & 0,01 & 0,01 & 0,01 & 0,01 & 0,01 & 0,01 & 0,01 & 0,02 \\
\hline Stellaria media & + & + & 0,01 & 0,02 & 0,01 & 0,01 & + & - & 0,01 & 0,01 \\
\hline Geranium pusilum & + & + & 0,01 & + & - & - & 0,01 & + & 0,01 & 0,01 \\
\hline Viola arvensis & + & 0,01 & + & + & 0,01 & + & + & + & 0,01 & 0,01 \\
\hline Lamium purpureum & + & + & 0,01 & 0,02 & 0,01 & 0,01 & + & 0,01 & - & - \\
\hline Lamium amplexicaule & + & + & + & + & + & + & 0,01 & + & 0,01 & + \\
\hline Fallopia convolvulus & + & + & + & + & + & + & 0,01 & + & + & - \\
\hline Veronica persicaria & + & + & + & + & + & + & - & + & - & 0,01 \\
\hline Thlaspi arvense & + & + & + & + & - & - & - & - & - & - \\
\hline $\begin{array}{l}\text { Matricaria maritima } \\
\text { sp. inodora }\end{array}$ & + & + & - & + & - & - & - & - & - & - \\
\hline Cirsium arvense & + & + & + & + & + & 0,02 & 0,01 & + & - & - \\
\hline Convolvulus arvense & + & + & 0,01 & 0,02 & - & - & - & - & - & - \\
\hline
\end{tabular}

+ wskaźnik dominacji (C) mniejszy niż 0,01 - dominance index (C) low than 0.01

- gatunek nie występował - species not record

Tabela 4. Wartości wskaźników biocenotycznych w dwóch odmianach 5 gatunków zbóż jarych (średnie z lat) Table 4. Values of $\mathrm{c}$ biocenotic index in 2 cultivars of 5 spring cerals (average from year)

\begin{tabular}{|c|c|c|c|c|c|c|c|c|c|c|}
\hline \multirow{2}{*}{$\begin{array}{l}\text { Wskaźniki } \\
\text { Coefficients }\end{array}$} & \multicolumn{2}{|c|}{$\begin{array}{c}\text { Pszenica } \\
\text { Wheat }\end{array}$} & \multicolumn{2}{|c|}{$\begin{array}{c}\text { Jęczmień } \\
\text { Barley }\end{array}$} & \multicolumn{2}{|c|}{$\begin{array}{l}\text { Owies } \\
\text { Oats }\end{array}$} & \multicolumn{2}{|c|}{$\begin{array}{c}\text { Pszenżyto } \\
\text { Triticale }\end{array}$} & \multicolumn{2}{|c|}{$\begin{array}{l}\text { Żyto } \\
\text { Rye }\end{array}$} \\
\hline & Tybalt & Parabola & Stratus & Mauritius & Arden & Haker & Nagano & Andrus & Arantas & Bojko \\
\hline $\mathrm{H}^{\prime}$ & 1,55 & 1,61 & 1,82 & 1,86 & 1,77 & 1,91 & 1,98 & 1,79 & 1,79 & 1,74 \\
\hline $\mathrm{C}$ & 0,32 & 0,28 & 0,20 & 0,18 & 0,26 & 0,22 & 0,25 & 0,22 & 0,19 & 0,20 \\
\hline $\mathrm{J}$ & 0,71 & 0,75 & 0,85 & 0,91 & 0,78 & 0,83 & 0,86 & 0,79 & 0,91 & 0,94 \\
\hline
\end{tabular}

H' - wskaźnik różnorodności - diversity index

$\mathrm{C}$ - wskaźnik dominacji - dominancie index

$\mathrm{J}$ - wskaźnik równomierności rozmieszczenia gatunków - uniform dispose weed species index

w jęczmieniu wynosił odpowiednio dla odmian: 0,01 i 0,03; a w pszenżycie: 0,02 i 0,08. Do ważniejszych gatunków zachwaszczających zboża zalicza się też przytulię czepną (Galium aparine) (Rola i wsp. 2000; Feledyn-Szewczyk 2011). Udział tego chwastu w strukturze zachwaszczenia, zależnie od gatunku i odmiany zbóż, mieścił się w zakresie 8,3-16,6\% (tab. 2), przy wskaźniku dominacji $\mathrm{C}$ nieprzekraczającym u większości gatunków 0,01 . Z innych częściej spotykanych chwastów należy wymienić: jasnotę purpurową (Lamium purpureum), jasnotę różową (L. amplexicaule), fiołka polnego (Viola arvensis), bodziszka drobnego (Geranium pusillum), tobołki polne (Thlaspi arvense) i rdestówkę powojową (Fallopia convolvulus). Dla większości tych gatunków wskaźnik dominacji C był mniejszy niż 0,01, co oznaczono, jako „,"; chociaż niektóre z nich występowały w liczbie powyżej 3 szt. $/ \mathrm{m}^{2}$. Podobny skład gatunkowy zachwaszczenia zbóż, charakterystyczny dla Dolnego Śląska podają też Rola i wsp. (2000). Taka liczebność w przypadku niektórych taksonów (np. G. aparine) jest uznawana za próg zagrożenia dla zbóż.

Analiza zbiorowisk chwastów za pomocą wskaźników różnorodności (H'), dominacji gatunkowej (C) i równomierności rozmieszczenia gatunków $(\mathrm{J})$, wskazuje na duże podobieństwo zbiorowisk chwastów w zbożach (tab. 4). Najniższy ogólny wskaźnik różnorodności H' $(1,55)$ stwierdzono w pszenicy odmiany Tybalt, zaś najwyższy $(1,98)$ w pszenżycie odmiany Nagano. Największe zróżnicowanie wartości tego wskaźnika pomiędzy odmianami zanotowano w owsie i pszenżycie. Wartość ogólnego wskaźnika dominacji chwastów $\mathrm{C}$ była wyższa w pszenicy $(0,28-0,32)$, a najniższa w jęczmieniu i życie $(0,18-0,20)$. Jest to potwierdzeniem faktu, iż żyto i jęczmień lepiej konkurują $\mathrm{z}$ chwastami niż pszenica. Wprawdzie liczebność taksonów i osobników chwastów w zbożach jarych oraz wartości wskaźników biocenotycznych zbiorowisk chwastów zależały od gatunku i odmiany, to 
różnice były niewielkie (tab. 1) i porównywane zbiorowiska charakteryzowały się dużą homogennością.

Niezależnie od zaobserwowanych różnic w opisywanych doświadczeniach poziom zachwaszczenia był na tyle wysoki, że konieczne były odpowiednie zabiegi odchwaszczające.

W przeprowadzonych badaniach wykazano, że w zbożach jarych uprawianych w stanowisku po rzepaku, głównym chwastem są samosiewy rośliny przedplonowej i Ch. album. Potwierdzono także, że gatunki i odmiany zbóż mogą różnić się pomiędzy sobą stanem i stopniem zachwaszczenia, co wynika $\mathrm{z}$ różnic $\mathrm{w}$ zdolności konkurencyjnej odmian wobec chwastów (Kapeluszny 1994; Christensen 1995; Hucl 1998; Feledyn-Szewczyk 2011; Kazikowski i Urban 2011), a na co wpływają także warunki siedliskowe oraz zabiegi agrotechniczne. $\mathrm{Na}$ zdolności konkurencyjne gatunków i odmian zbóż poza właściwościami genotypu, czynnikami agrotechnicznymi i siedliskowymi może mieć także modyfikujący wpływ przebieg pogody w okresie wegetacji.

\section{Wnioski / Conclusions}

W zbożach jarych uprawianych w stanowisku po rzepaku, niezależnie od ich gatunków i odmian, liczba taksonów kształtowała się na podobnym poziomie, natomiast liczebność i biomasa chwastów była zróżnicowana. Największe zachwaszczenie wyrażone zarówno ogólną liczbą chwastów, jak i biomasą odnotowano w pszenicy jarej, a najmniejsze w jęczmieniu i w życie. Wynika to $\mathrm{z}$ różnic $\mathrm{w}$ obsadzie roślin zbóż i ich wysokości oraz zdolności do rozkrzewiania się po wschodach. Odnotowano też różnice w liczbie i biomasie chwastów pomiędzy odmianami w obrębie porównywanych gatunków zbóż. W największej liczebności występowały: B. napus var. oleifera (samosiewy rzepaku) i Ch. album. Zbiorowiska chwastów scharakteryzowane za pomocą wskaźników biocenotycznych wykazywały duże podobieństwo, a zróżnicowanie gatunkowe było stosunkowo niewielkie.

\section{Literatura / References}

Abouziena H.F., Sharara Faida A.A., El-desoki E.R. 2008. Efficacy of cultivar selectivity and weed control treatments on wheat yield and associated weeds in sandy soils. World J. Agric. Sci. 4 (3): 384-389.

Christensen S. 1994. Crop weeds competition and herbicide performance in cereal species and varietes. Weed Res. 34 (1): $29-36$.

Christensen S. 1995. Weed suppression ability of spring barley varieties. Weed Res. 35 (4): 241-247.

Falińska K. (red.) 2004. Przestrzenna bioróżnorodność zbiorowisk. s. 272-284. W: „Ekologia Roślin”. PWN, Warszawa, 453 ss.

Feledyn-Szewczyk B., Duer I. 2005. Konkurencyjność kilku odmian pszenicy ozimej uprawianej w ekologicznym systemie produkcji w stosunku do chwastów. Prog. Plant Prot./Post. Ochr. Roślin 45 (1): 126-133.

Feledyn-Szewczyk B. 2011. Zachwaszczenie odmian pszenicy jarej uprawianej w ekologicznym systemie produkcji. J. Res. Appl. Agric. Eng. 56 (3): 72-76.

Hucl P. 1998. Response to weed control by four spring wheat genotypes differing in competitive ability. Can. J. Plant Sci. 78 (1): 171-173.

Jędruszczak M., Bojarczyk M., Smolarz H.J., Budzyńska B. 2004. Konkurencyjne zdolności pszenicy ozimej wobec chwastów w warunkach różnych sposobów odchwaszczania - produkcja biomasy. Ann. UMCS, Sec. E, 59 (2): 895-902.

Kapeluszny J. 1994. Kształtowanie się struktury plonu i łanu jęczmienia jarego i jarej pszenicy w zależności od stopnia zachwaszczenia. s. 95-100 W: 17. Krajowa Konferencja „Przyczyny i źródła zachwaszczenia pól uprawnych”. Olsztyn-Bęsia, 28-29.06.1994. ART, Olsztyn, $151 \mathrm{ss}$.

Kazikowski P., Urban M. 2011. Ocena zachwaszczenia odmian pszenicy ozimej w zależności od ich pokroju i terminów siewu. Prog. Plant Prot./Post. Ochr. Roślin 51 (1): 458-463.

Lemerle D., Verbeek B., Cousens R.D., Coombes N.E. 1996. The potential for selecting wheat varieties strongly competitive against weeds. Weed Res. 36: 505-513.

Markow M. 1978. Agrofitocenologia Nauka o Zbiorowiskach Roślinnych. PWRiL, Warszawa, 267 ss.

Mennan H., Zandstra B.H. 2005. Effect of wheat (Triticum aestivum) cultivars and seeding rate on yield loss from Galium aparine (cleavers). Crop Prot. 24: 1061-1067.

Parylak D., Zawieja J., Jędruszczak M., Stupnicka-Rodzynkiewicz E., Dąbkowska T., Snarska K. 2006. Wykorzystanie zasiewów mieszanych, własności odmian lub zjawiska allelopatii w ograniczaniu zachwaszczenia. Prog. Plant Prot./Post. Ochr. Roślin 46 (1): $33-44$.

Rola J., Rola H., Badowski M. 2000. Zbiorowiska segetalne na polach gospodarstw ekologicznych i tradycyjnych Dolnego Śląska. Pam. Pul. 122: 21-29.

Rudnicki F. 1994. Biologiczne aspekty uprawy zbóż w mieszankach. s. 7-15. W: Mat. Konf. „Stan i perspektywy uprawy mieszanek zbożowych". AR, Poznań, 02.12.1994, 197 ss.

Seavers G.P., Wright K.J. 1999. Crop canopy development and structure influences weed suppression. Weed Res. 39: 319-328.

Shannon C.E., Weaver W. 1963. The Mathematic Theory of Communication. Urbana, Univ. of Ilionois Press, 108 pp.

Smith R.J. 1974. Competition of barnyard grass with rice cultivars. Weed Sci. 16 (2): 252-254.

Sweet R.D. 1976. When it comes to competing with weeds, some are more equal than others. Crops and Soils 28 (6): 7-9.

Wicks G.A., Nordquist P.T., Baenziger P.S., Klein R.N., Hammons R.H., Watkins J.E. 2004. Winter wheat cultivar characteristics affect annual weed suppression. Weed Tech. 18: 988-998. 